\title{
Carotid, Not Aortic, Chemoreceptors Mediate the Fetal Cardiovascular Response to Acute Hypoxemia in Lambs
}

\author{
BEATRIJS BARTELDS, FRANK VAN BEL, DAVID F. TEITEL, AND ABRAHAM M. RUDOLPH \\ Department of Pediatrics and Cardiovascular Research Institute, University of California, San Francisco, \\ San Francisco, California 94143-0544
}

\begin{abstract}
The fetal cardiovascular response to acute hypoxemia consists of a decrease in heart rate, a variable change in mean arterial pressure, and an increase in peripheral vascular resistance. This response is mediated by the arterial chemoreceptors. To determine whether chemoreceptors in the carotid artery or in the aorta mediate the fetal cardiovascular response to acute hypoxemia, we studied the response to acute hypoxemia in fetal lambs at $\mathbf{1 2 5}$ to $130 \mathrm{~d}$ of gestation after selective carotid (six fetuses) or aortic (five fetuses) denervation. One to $3 \mathrm{~d}$ after insertion of catheters, hypoxemia was induced by inflating a balloon occluder around the ewe's hypogastric artery or by giving the ewe $95 \% \mathrm{~N}_{2}$ and $5 \% \mathrm{O}_{2}$ to breathe. The chemoreflex response was measured as decrease in heart rate per decrease in $\mathrm{Hb} \mathrm{O}_{2}$ saturation. To validate our results, we also studied the response to chemical stimulation of the chemoreceptors by injection of sodium cyanide into the inferior vena cava. We found that carotid denervation abolished the heart rate and peripheral vascular resistance responses to hypoxemia but that aortic denervation did not. Responses after injection of sodium cyanide were similar to those seen during acute hypoxemia. We conclude that the carotid chemoreceptors, and not the aortic chemoreceptors, mediate the fetal cardiovascular response to acute hypoxemia. (Pediatr Res 34: 51-55, 1993)
\end{abstract}

\section{Abbreviations}

$\Delta \mathrm{HR} / \Delta \mathrm{SaO}_{2}$, decrease in heart rate to decrease in oxygen saturation

$\Delta H R / \Delta B P$, decrease in heart rate to increase in mean arterial pressure

$\mathrm{NaCN}$, sodium cyanide

The fetal cardiovascular response to acute hypoxemia consists of a decrease in heart rate, a variable change in mean arterial pressure, an increase in peripheral vascular resistance, and a redistribution of blood flow (1-3). The changes in heart rate are mediated by arterial chemoreceptors located in the common carotid artery and aortic arch (4-6). Changes in arterial pressure, peripheral vascular resistance, and blood flow redistribution are mediated in part by chemoreceptors, but also by local mechanisms (3). However, whether the carotid or the aortic chemore-

Received September 10, 1992; accepted February 18, 1993.

Correspondence and reprint requests: Abraham M. Rudolph, M.D. Box 0544 , HSE 1403, University of California, San Francisco, San Francisco, CA 94143-0544.

Supported by PHS Grant HL-35842, from the National Institutes of Health, and by the University of California, San Francisco Academic Senate Committee on Research. ceptors mediate the fetal response to acute hypoxemia has not been clearly established.

Based on studies in fetal lambs, Dawes et al. (7) suggested that the aortic chemoreceptors mediate the response to acute hypoxemia. They also suggested that the carotid chemoreceptors are inactive in the fetal physiologic range (8), although carotid-nerve activity has been recorded in fetal lambs (9). However, all of these experiments were performed in acutely exteriorized fetal lambs, whereas the ewe was given chloralose anesthesia. The effects of exteriorization and anesthesia may have influenced the results.

The aim of this study was to determine whether chemoreceptors located in the carotid artery or in the aorta mediate the fetal cardiovascular response to acute hypoxemia. To avoid any effects of exteriorization and anesthesia, we studied the response to hypoxemia in six carotid- and five aortic-chemoreceptor-denervated fetal lambs chronically instrumented in utero at 125 to 130 d of gestation. To validate our results, we also studied the response to chemical stimulation of the chemoreceptors by injection of $\mathrm{NaCN}$ into the inferior vena cava. The surgical denervation procedure destroys not only chemoreceptor afferent nerves, but also baroreceptors from the aortic and carotid regions.

\section{MATERIALS AND METHODS}

Surgical preparation. Eleven fetal lambs at 125 to $130 \mathrm{~d}$ of gestation were studied. All procedures were approved by the Committee on Animal Research of the University of California, San Francisco. Ewes were given epidural anesthesia with $4 \mathrm{~mL}$ of $2 \%$ tetracaine hydrochloride. Ketamine hydrochloride was given i.v. in doses of $100 \mathrm{mg}$ every 10 to $15 \mathrm{~min}$ to maintain sedation. Through a midline abdominal incision, the maternal descending aorta was exposed at the iliac bifurcation. The common hypogastric artery, from which the uterine arteries originate, was isolated, and an inflatable balloon occluder was placed around it.

Through a small uterine incision, the right fetal hind limb was exposed, and polyvinyl catheters (internal diameter $1.3 \mathrm{~mm}$, outside diameter $2.3 \mathrm{~mm}$ ) were inserted into the descending aorta and inferior vena cava via a pedal artery and vein for pressure measurements and injection of $\mathrm{NaCN}$, respectively. Lidocaine $(0.5 \%)$ was injected s.c. before all fetal skin incisions. Ketamine $\mathrm{HCl}$ was also given intramuscularly to the fetus in doses of $5 \mathrm{mg} / \mathrm{kg}$ estimated fetal weight; this dose was repeated every 15 to $20 \mathrm{~min}$. In seven of the 11 fetuses, a Transonic Doppler flow transducer (Transonic Systems, Ithaca, NY) was placed around the left iliac artery through an incision in the left flank. A catheter was placed in the amniotic cavity for zero pressure reference, and the uterine incision was closed.

Through another uterine incision, the fetal head and neck were exposed. An incision was made on one side of the head caudal to the jaw. To prevent fetal respiratory movement, $10 \mathrm{mg}$ suc- 
cinyl choline was injected into the fetal inferior vena cava. In six fetuses, the carotid artery was denervated, and in the other five, the aorta was denervated as described previously (5). Briefly, the carotid artery was stripped of all nervous and connective tissue from about $1 \mathrm{~cm}$ rostral to the origin of the lingual artery to about $1 \mathrm{~cm}$ caudal to the origin of the occipital artery. To denervate the aorta, the aortic nerve, along with the superior laryngeal nerve, was cut at the point where the two nerves join, just below the nodose ganglion. The same procedure was performed on the other side of the neck.

A polyvinyl catheter (internal diameter $0.3 \mathrm{~mm}$, outside diameter $0.5 \mathrm{~mm}$ ) was advanced to the ascending aorta via the brachial artery for blood sampling. For continuous measurement of $\mathrm{O}_{2}$ saturation, a 4F Oximetrix saturation catheter (Abbott Critical Care Systems, Mountain View, CA) was inserted into the carotid artery. Warm $0.9 \% \mathrm{NaCl}$ solution, to replace the lost amniotic fluid, and antibiotics (50 mg gentamicin, $2 \times 10^{6} \mathrm{IU}$ penicillin G) were instilled in the amniotic cavity. Antibiotics in the same doses were given daily in the amniotic fluid and the maternal vein. All vascular catheters were filled with heparin sodium solution $(500 \mathrm{IU} / \mathrm{mL})$ and sealed. The catheters were then exteriorized to the maternal flank and protected by a cloth pouch, and the abdominal incision was closed. The fetus was studied 1 to $3 \mathrm{~d}$ postoperatively.

Protocol. Heart rate, peripheral blood flow, and mean arterial pressure responses to hypoxemia were studied repeatedly. For each study, the ewe was placed in a cart and allowed free access to food and water. Heart rate, arterial blood pressure, and blood flow in the iliac artery (for calculation of peripheral vascular resistance), and $\mathrm{PO}_{2}, \mathrm{PCO}_{2}, \mathrm{pH}, \mathrm{Hb}$ concentration, and $\mathrm{Hb} \mathrm{O}_{2}$ saturation were measured continuously. After baseline measurements, we induced hypoxemia either by inflating the balloon occluder around the ewe's common hypogastric artery or by giving the ewe a gas mixture of $95 \% \mathrm{~N}_{2}$ and $5 \% \mathrm{O}_{2}$ to breathe. Within 5 to $30 \mathrm{~s}, \mathrm{Hb} \mathrm{O}_{2}$ saturation in the fetal carotid artery started to fall. Forty-five $\mathrm{s}$ after the drop in $\mathrm{Hb} \mathrm{O}_{2}$ saturation, when heart rate was expected to be at its nadir (10), heart rate, peripheral blood flow, and mean arterial pressure and resistance were assessed, and a blood sample was withdrawn. Then the mother was allowed to breathe air for 10 to $15 \mathrm{~min}$ before additional studies were performed.

In addition, to validate our results, we injected $\mathrm{NaCN}(50-300$ $\mu \mathrm{g})$, a chemical stimulant of the chemoreceptors, into the fetal inferior vena cava and measured the same variables as before.

To assess the influence of selective denervation on baroreceptors, we injected phenylephrine (10-30 $\mu \mathrm{g}$ ) into the inferior vena cava in five of the carotid-denervated and in the five aorticdenervated fetal lambs and measured the same variables.

Measurements. Heart rate was obtained from the arterial pressure pulse, which triggered a cardiotachometer. Mean arterial blood pressure and amniotic pressure were measured by straingauge transducers. Peripheral blood flow was measured by a flow probe connected to a Transonic flowmeter. The time course of changes in $\mathrm{Hb} \mathrm{O}_{2}$ saturation was followed with the $\mathrm{O}_{2}$ saturation catheter, which was connected to an $\mathrm{SO}_{2} / \mathrm{CO}$ Oximetrix computer (Abbot Critical Care Systems). All signals were recorded on a Beckman recorder (Beckman Instruments, Fullerton, CA).

Exact values of $\mathrm{Hb} \mathrm{O}_{2}$ saturation and $\mathrm{Hb}$ concentration (Radiometer OSM2 hemoximeter, Copenhagen, Denmark) and pH, $\mathrm{PCO}_{2}$, and $\mathrm{PO}_{2}$ (Corning $158 \mathrm{pH} /$ blood gas analyzer, Medfield, MA) were determined from the ascending aortic blood samples.

Data analysis. The heart-rate response to hypoxemia is expressed as decrease in heart rate per decrease in $\mathrm{Hb} \mathrm{O}_{2}$ saturation $\left(\Delta \mathrm{HR} / \Delta \mathrm{SaO}_{2}\right)(10)$. Vascular resistance of the hind limb was calculated as mean arterial blood pressure divided by iliac arterial blood flow in five carotid- and two aortic-denervated fetal lambs.

To analyze the response to $\mathrm{NaCN}$ injection, the maximal decrease in heart rate in each fetal lamb was used. To analyze the response to phenylephrine injection, the ratio of the decrease in heart rate per increase in mean arterial pressure $(\Delta H R / \Delta B P)$ was calculated, and the minimum value of this ratio was used for analysis.

Data are presented as mean $\pm \mathrm{SD}$. The unpaired $t$ test was used to test for differences between the carotid-denervated and the aortic-denervated fetal lambs. Four hypoxic episodes from each animal were used for the analysis. The paired $t$ test was used to test for the response to hypoxemia or to $\mathrm{NaCN}$ injection in the carotid- and aortic-denervated fetal lambs.

\section{RESULTS}

On the day of the study, there were no differences in gestational age or postoperative days between the carotid- and the aorticdenervated fetal lambs. Also, baseline blood gases, $\mathrm{pH}, \mathrm{Hb} \mathrm{O}_{2}$ saturation, and $\mathrm{Hb}$ concentration were the same in the two groups, and were similar to those of normal lambs (Table 1). The same was true for baseline heart rate and hind-limb vascular resistance (Table 2), but baseline mean arterial blood pressure was slightly higher in the carotid- than in the aortic-denervated fetal lambs.

The heart-rate response to hypoxemia in fetal lambs in utero was abolished by carotid denervation, but was not altered by aortic denervation. No significant decrease in heart rate occurred during hypoxemia in the carotid-denervated lambs; the $\Delta \mathrm{HR} /$ $\Delta \mathrm{SaO}_{2}$ was $0.35 \pm 1.0$ (mean $\pm \mathrm{SD}$ ) for 24 occlusions in the six carotid-denervated lambs (Fig. 1). In contrast, in the aorticdenervated fetal lambs, heart rate decreased with the decrease in $\mathrm{Hb} \mathrm{O}_{2}$ saturation, as it does in normal lambs (10). The $\Delta \mathrm{HR} /$ $\Delta \mathrm{SaO}_{2}$ was $2.79 \pm 1.57(p<0.0001)$ for 20 occlusions in the five aortic-denervated lambs.

Like the heart-rate response to hypoxemia, the heart-rate response to $\mathrm{NaCN}$ injection was abolished by carotid denervation, but not by aortic denervation. A typical tracing of the response to $\mathrm{NaCN}$ injection shows no decrease in heart rate in the carotid-denervated fetal lambs, but a sharp decrease in heart rate in the aortic-denervated fetal lambs (Fig. 2). The maximal decrease in heart rate after $\mathrm{NaCN}$ injection was $10 \pm 10$ beats/ $\mathrm{min}$ in the carotid-denervated lambs, but $114 \pm 42$ beats/min $(p<0.001)$ in the aortic-denervated fetal lambs.

In the five carotid-denervated fetal lambs in which hind-limb vascular resistance was calculated, hind-limb vascular resistance did not increase in response to hypoxemia after carotid denervation. However, in the two lambs with aortic denervation, hindlimb vascular resistance did increase, as in normal fetal lambs (Table 2). The responses of hind-limb vascular resistance to $\mathrm{NaCN}$ injection were calculated in two aortic-denervated and in

Table 1. Baseline hemodynamic values and blood gases in carotid-and aortic-denervated fetal lambs*

\begin{tabular}{lcc}
\hline \multicolumn{1}{c}{ Variable } & $\begin{array}{c}\text { Carotid- } \\
\text { denervated }\end{array}$ & $\begin{array}{c}\text { Aortic- } \\
\text { denervated }\end{array}$ \\
\hline $\mathrm{PO}_{2}$ & & \\
$\mathrm{kPa}$ & $2.9 \pm 0.5$ & $3.3 \pm 0.8$ \\
$\mathrm{torr}$ & $22.4 \pm 3.6$ & $25 \pm 5.9$ \\
$\mathrm{PCO}_{2}$ & & \\
$\mathrm{kPa}$ & $6.7 \pm 0.6$ & $6.4 \pm 0.4$ \\
torr & $50.4 \pm 4.5$ & $48.2 \pm 3.0$ \\
$\mathrm{pH}$ & $7.40 \pm 0.05$ & $7.42 \pm 0.03$ \\
$\mathrm{Hb}$ oxygen saturation $(\%)$ & $59 \pm 9$ & $64 \pm 13$ \\
$\mathrm{Hb}$ concentration $(\mathrm{g} / \mathrm{L})$ & $107 \pm 12$ & $103 \pm 15$ \\
$\mathrm{Heart}$ rate (beats/min) & $184 \pm 29$ & $177 \pm 23$ \\
Peripheral blood flow (mL/min) & $34 \pm 10$ & $39 \pm 10$ \\
Mean arterial blood pressure $(\mathrm{mm} \mathrm{Hg})$ & $53 \pm 7$ & $48 \pm 6 \dagger$ \\
\hline
\end{tabular}

* Data are means \pm SD for 24 measurements in the six carotiddenervated fetuses and 20 measurements in the five aortic-denervated fetuses, except that for peripheral blood flow, there were 17 and eight measurements, respectively.

$\dagger p<0.05 v s$ carotid-denervated fetuses by unpaired $t$ test. 
Table 2. Cardiovascular responses to hypoxemia in carotid-and aortic-denervated fetal lambs in utero*

\begin{tabular}{|c|c|c|c|}
\hline Response & $n$ & Baseline & Hypoxemia \\
\hline \multicolumn{4}{|c|}{ Mean arterial blood pressure $(\mathrm{mm} \mathrm{Hg})$} \\
\hline Carotid-denervated fetuses & 24 & $53 \pm 7$ & $53 \pm 8$ \\
\hline Aortic-denervated fetuses & 20 & $48 \pm 6 \dagger$ & $47 \pm 6+$ \\
\hline \multicolumn{4}{|l|}{ Peripheral blood flow $(\mathrm{mL} / \mathrm{min})$} \\
\hline Carotid-denervated fetuses & 17 & $34 \pm 10$ & $33 \pm 15$ \\
\hline Aortic-denervated fetuses & 8 & $39 \pm 10$ & $16 \pm 15 t$ \\
\hline \multicolumn{4}{|c|}{ Peripheral vascular resistance $(\mathrm{mm} \mathrm{Hg} / \mathrm{min} / \mathrm{mL}$ ) } \\
\hline Carotid-denervated fetuses & 17 & $1.6 \pm 0.5$ & $2.0 \pm 1.3$ \\
\hline Aortic-denervated fetuses & 8 & $1.5 \pm 0.4$ & $4.0 \pm 3.2 \dagger$ \\
\hline
\end{tabular}

* Data are means \pm SD for the six carotid- and five aortic-denervated fetal lambs (mean arterial blood pressure) and for five of the carotid- and two of the aortic-denervated fetal lambs (peripheral blood flow and peripheral vascular resistance). $n=$ number of experiments.

$+p<0.05$ is carotid-denervated fetuses by unpaired $t$ test.
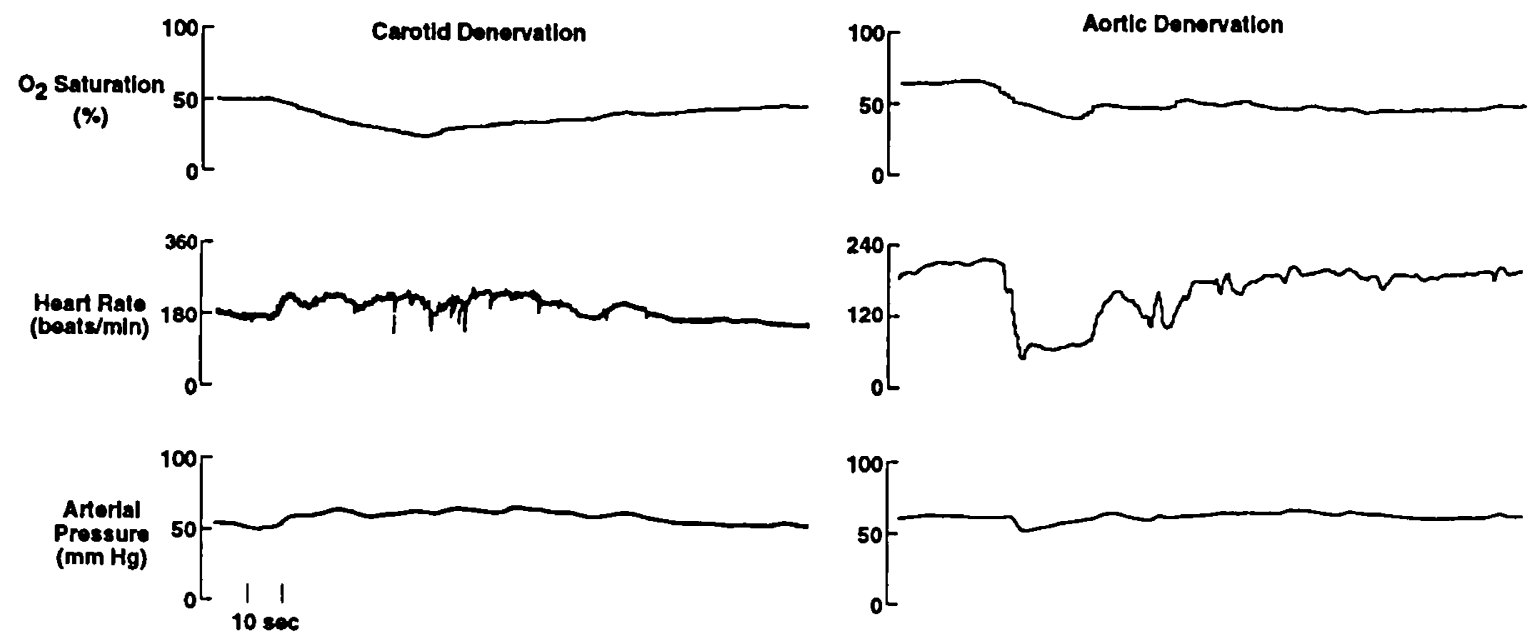

Fig. 1. Responses to acute hypoxemia after selective carotid or aortic deafferentiation in fetal lambs. With carotid denervation, heart rate does not fall as arterial $\mathrm{O}_{2}$ saturation falls, but actually increases. With selective aortic denervation, heart rate falls dramatically with the decrease in arterial $\mathrm{O}_{2}$ saturation.
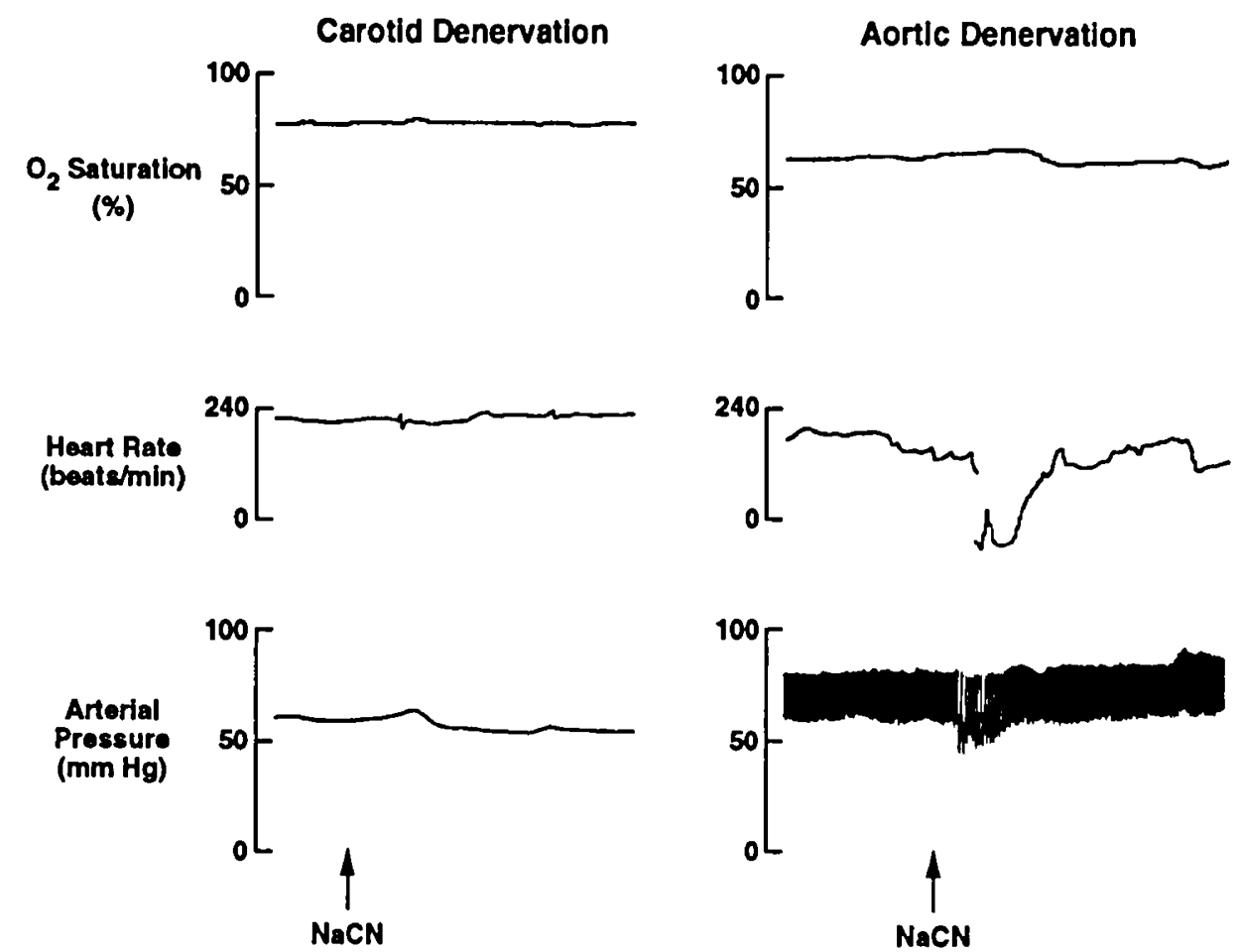

Fig. 2. Responses to $\mathrm{NaCN}$ injection in fetal lambs with selective carotid or aortic deafferentiation. After carotid denervation, no change in heart rate is induced by cyanide, but heart rate falls dramatically with cyanide after aortic denervation. 
three carotid-denervated fetal lambs; these were similar to the responses observed with hypoxemia.

The baroreceptor response was abolished in the carotid-denervated fetal lambs, but was not changed in the aortic-denervated fetal lambs. The $\Delta H R / \Delta B P$ response was lower in the carotiddenervated $(-0.21 \pm 1.70)$ than in the aortic-denervated fetal lambs $(-3.21 \pm 2.07 ; p<0.05)$. Interestingly, the blood pressure increased more with a lower dose of phenylephrine in the carotiddenervated than in the aortic-denervated fetal lambs. In the carotid-denervated animals, an i.v. injection of $12 \pm 5 \mu \mathrm{g}$ increased mean arterial blood pressure by $20 \pm 10 \mathrm{~mm} \mathrm{Hg}$, whereas in the aortic-denervated lambs, an i.v. injection of $22 \pm 5 \mu \mathrm{g}$ increased mean arterial pressure by only $10 \pm 3 \mathrm{~mm} \mathrm{Hg}(p<$ $0.05)$.

\section{DISCUSSION}

In this study of selectively denervated fetal lambs in utero, we have shown that carotid chemoreceptors, not aortic chemoreceptors, mediate the fetal cardiovascular response to acute hypoxemia. In our fetal lambs, denervation of the carotid artery abolished the normal heart-rate and peripheral vascular-resistance responses to acute hypoxemia, whereas aortic deafferentiation did not alter these responses. Specifically, heart rate did not decrease during hypoxemia in carotid-denervated fetal lambs but did decrease in aortic-denervated fetal lambs, as it does in normal fetal lambs. Similarly, peripheral vascular resistance did not increase during hypoxemia in carotid-denervated fetal lambs but did increase in aortic-denervated fetal lambs. In addition, after $\mathrm{NaCN}$ injection, heart rate did not decrease in carotid-denervated fetal lambs but did decrease in aortic-denervated fetal lambs.

In contrast to our results, Dawes et al. (7) suggested that the response to acute hypoxemia is mediated entirely by the aortic and not by the carotid chemoreceptors. However, the fetal lambs they studied were hyperoxemic instead of normoxemic; their baseline arterial $\mathrm{PO}_{2}$ was $37.8 \pm 0.5 \mathrm{~mm} \mathrm{Hg}(5.0 \pm 0.1 \mathrm{kPa}$, mean \pm SEM), which is far above the baseline arterial $\mathrm{PO}_{2}$ of $22.4 \pm 3.6 \mathrm{~mm} \mathrm{Hg}(2.9 \pm 0.5 \mathrm{kPa}$, mean $\pm \mathrm{SD})$ in our fetal lambs. The higher baseline $\mathrm{PO}_{2}$ in their fetuses is probably due to the fact that they ventilated the ewes with a high- $\mathrm{O}_{2}$ gas mixture, whereas we studied in utero fetal lambs while the ewe was breathing room air. In addition, they induced only mild hypoxemia, lowering the fetal arterial $\mathrm{Po}_{2}$ to $28.4 \pm 0.9 \mathrm{~mm} \mathrm{Hg}$ $(3.8 \pm 0.1 \mathrm{kPa})$ whereas the $\mathrm{PO}_{2}$ in our fetal lambs was lowered to $15.2 \pm 2.8 \mathrm{~mm} \mathrm{Hg}(2.0 \pm 0.4 \mathrm{kPa})$. As a result, they observed a different response to hypoxemia in normal fetal lambs than we did; i.e. they observed an increase in heart rate, whereas we observed a decrease in heart rate in normal fetal lambs in response to hypoxemia $(1,3,5,6,10)$. In concordance with our results, Dawes et al. (8) also observed that the response to $\mathrm{NaCN}$ injection, a decrease in heart rate and an increase in peripheral vascular resistance, was abolished by carotid denervation, but not by aortic denervation. Based upon these results, they concluded that the carotid chemoreceptors were active in fetal lambs in utero, but only at low arterial $\mathrm{PO}_{2}$. However, in this study, we show that the carotid chemoreceptors are active in fetal lambs in utero under physiologic conditions and that the carotid chemoreceptors, and not the aortic chemoreceptors, mediate the fetal cardiovascular response to acute hypoxemia.

We observed a relationship between heart rate and peripheral blood flow: in the aortic-denervated fetal lambs, the decrease in heart rate during hypoxemia was always accompanied by a decrease in peripheral blood flow. We did not explore whether the decrease in peripheral blood flow during hypoxemia in the aortic-denervated fetal lambs was caused by the decrease in heart rate or was due to a chemoreceptor-mediated increase in peripheral vascular resistance. However, calculated peripheral vascular resistance increased during hypoxemia in the aortic-denervated fetal lambs. Furthermore, Dawes et al. (8) reported that cervical vagotomy abolished the decrease in heart rate but not the increase in peripheral vascular resistance in response to $\mathrm{NaCN}$ injection. These findings suggest that the decrease in peripheral blood flow during hypoxemia in the aortic-denervated fetal lambs may have been due to a chemoreceptor-mediated increase in peripheral vascular resistance.

Surprisingly, the carotid-denervated fetal lambs had a slightly higher baseline mean arterial blood pressure than did the aorticdenervated fetal lambs. The mean arterial blood pressure in our aortic-denervated fetal lambs was similar to that of normal fetal lambs $(3,11,12)$ and to that of fetal lambs whose carotid and aortic chemoreceptors have been denervated $(3,5)$. The higher baseline mean arterial pressure cannot be explained by age differences because there were no differences in gestational age between the different groups. In the previous studies, however, the lambs were studied 3 to $4 \mathrm{~d}$ postoperatively, whereas we studied the lambs 1 to $3 \mathrm{~d}$ postoperatively. Although this time difference could have an influence, it does not explain the difference in mean arterial pressure between the two groups in this study, because there was no difference in elapsed postoperative days between the carotid-denervated and the aortic-denervated fetal lambs. One possible explanation is that the baroreceptor afferents are abolished along with the chemoreceptors. Denervation of the carotid baroreceptors blocks the inhibitory input to vascular tone, which can lead to an increase in mean arterial blood pressure. This explanation is likely because the baroreceptor response, tested by injection of phenylephrine, is also abolished by carotid denervation but not by aortic denervation.

Our findings imply that the aortic baroreceptors, like the aortic chemoreceptors, are not functional in fetal lambs in utero. Nonfunctional aortic chemoreceptors and baroreceptors could be a specific feature of the sheep species. However, Kumar and Hanson (13) recorded chemoreceptor activity from the aortic nerve in newborn lambs. It is possible that aortic receptors are not functioning during fetal life and that they become functional after birth. It is also possible that although aortic-receptor activity is present, it has no effect on circulatory responses.

After birth, the response to acute hypoxemia differs markedly from that during fetal life. Specifically, after birth, both ventilation and heart rate increase in response to hypoxemia (14), whereas in the fetus, heart rate decreases in response to hypoxemia and there is minimal ventilatory response. The difference in heart-rate response could be due to either the difference in ventilation or differences in chemoreceptor sensitivity in the aortic or carotid bodies. Evidence exists to support both possibilities. In newborn lambs, an increase in ventilation stimulates pulmonary stretch receptors and thus can counteract the chemoreceptor-induced decrease in heart rate (15). However, resetting of the aortic and carotid chemoreceptor bodies after birth, as measured by their nerve activities, has been reported in newborn lambs $(9,13)$. The functional changes underlying the difference in response to hypoxemia between the fetus and the newborn remain to be elucidated.

In conclusion, in selectively denervated fetal lambs in utero, we have shown that the carotid, and not the aortic, chemoreceptors mediate the fetal cardiovascular response to acute hypoxemia. This finding implies that the aortic chemoreceptors are not functional in fetal lambs in utero. Even though hypoxemia increases impulse activity in the aortic nerve in newborn lambs (13), whether aortic chemoreceptors play a role in the circulatory and ventilatory responses to hypoxemia in the newborn remains to be elucidated.

\section{REFERENCES}

1. Cohn HE, Sacks EJ, Heymann MA, Rudolph AM 1974 Cardiovascular responses to hypoxemia and acidemia in fetal lambs. Am J Obstet Gynecol 120:817-824

2. Itskovitz J, Goetzman BW, Rudolph AM 1982 The mechanism of late deceleration of the heart rate and its relationship to oxygenation in normoxemic and chronically hypoxemic fetal lambs. Am J Obstet Gynecol 142:66-73

3. Itskovitz J, LaGamma EF, Bristow J, Rudolph AM 1991 Cardiovascular 
responses to hypoxemia in sinoaortic-denervated fetal sheep. Pediatr Res 30:381-385

4. Rudolph AM 1984 The fetal circulation and its response to stress. J Dev Physiol 6:11-19

5. Itskovitz J, Rudolph AM 1982 Denervation of arterial chemoreceptors and baroreceptors in fetal lambs in utero. Am J Physiol 242:H916-H920

6. Itskovitz J, Rudolph AM 1987 Cardiorespiratory response to cyanide of arterial chemoreceptors in fetal lambs. Am J Physiol 252:H916-H922

7. Dawes GS, Duncan SLB, Lewis BV, Merlet CL, Owen-Thomas JB, Reeves JT 1969 Hypoxaemia and aortic chemoreceptor function in foetal lambs. J Physiol (Lond) 201:105-116

8. Dawes GS, Duncan SB, Lewis BV, Merlet CL, Owen-Thomas JB, Reeves JT 1969 Cyanide stimulation of the systemic arterial chemoreceptors in foetal lambs. J Physiol (Lond) 201:117-128

9. Blanco CE, Dawes GS, Hanson MA, McCooke HB 1984 The response to hypoxia of arterial chemoreceptors in fetal sheep and new-born lambs. J Physiol (Lond) 351:25-37

10. Boekkooi PF, Baan Jr J, Teitel D, Rudolph AM 1992 Chemoreceptor responsiveness in fetal sheep. Am J Physiol 263:H162-H167

11. Iwamoto HS, Rudolph AM, Keil LC, Heymann MA 1979 Hemodynamic responses of the sheep fetus to vasopressin infusion. Circ Res 44:430-436

12. Itskovitz J, LaGamma EF, Rudolph AM 1987 Effects of cord compression on fetal blood flow distribution and $\mathrm{O}_{2}$ delivery. Am J Physiol 252:H100- $\mathrm{H} 109$

13. Kumar P, Hanson MA 1989 Re-setting of the hypoxic sensitivity of aortic chemoreceptors in the new-born lamb. J Dev Physiol 11:199-206

14. Sidi D, Kuipers JRG, Teitel D, Heymann MA, Rudolph AM 1983 Developmental changes in oxygenation and circulatory responses to hypoxemia in lambs. Am J Physiol 245:H674-H682

15. Walker AM, Cannata JP, Dowling MH, Ritchie BC, Maloney JE 1979 Agedependent pattern of autonomic heart rate control during hypoxia in fetal and newborn lambs. Biol Neonate 35:198-208 